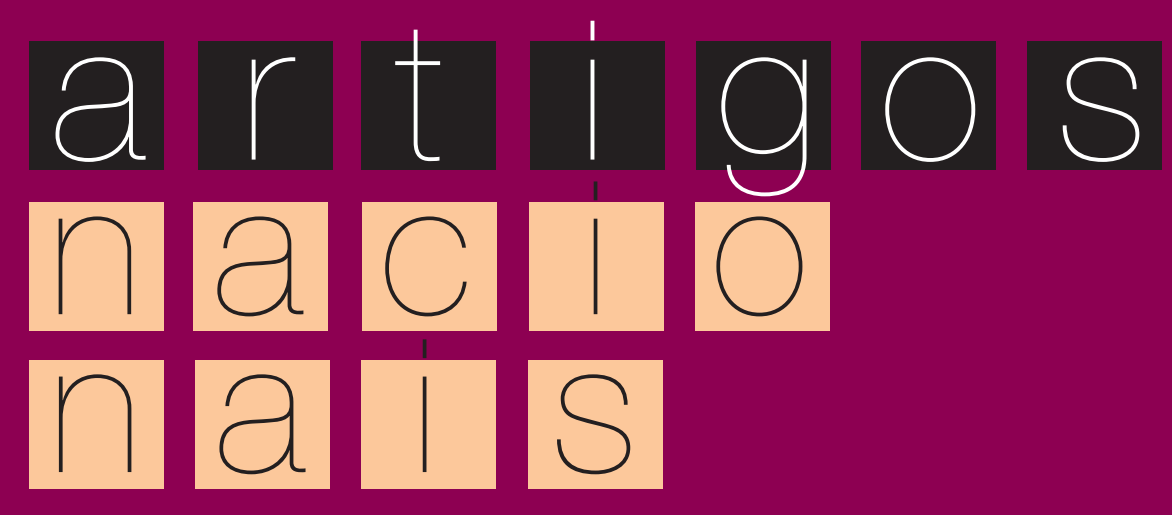


AÇÃO MIDIÁTICA, n.12. Jul./Dez. 2016. Curitiba. PPGCOM-UFPR. ISSN 2238-0701

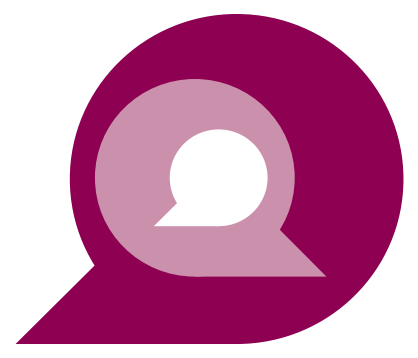




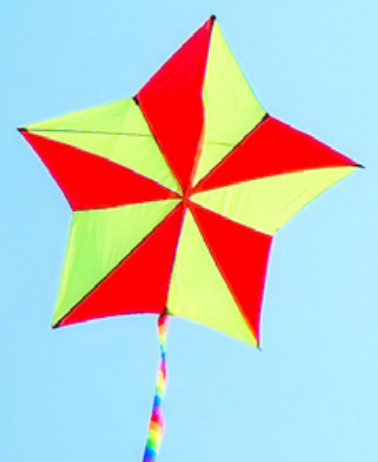

i 
Dispositivos móveis. Educação de Jovens e Adultos.

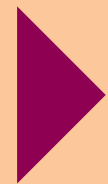




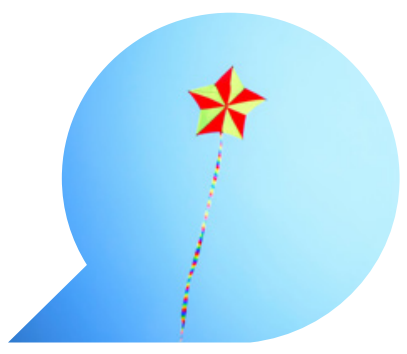

\section{Entre os dispositivos móveis interconectados e os processos de comunicação e aprendizagem ubíquas: a Educação de Jovens e Adultos na modalidade EAD}

Among the interconnected mobile devices and the processes of ubiquitous communication and learning: Youth and Adult Education in the distance educacion mode

Entre los dispositivos interconectados móviles y los procesos de comunicación y aprendizaje ubicuo: jóvenes y adultos en la modalidad de educación a distancia

\begin{tabular}{c}
\hline VALÉRIA CRISTINA DE CASTRO GABRIEL $^{1}$ \\
\hline EDUARDO FOFONCA $^{2}$ \\
\hline PATRICIA DANIELA MACIEL ${ }^{3}$
\end{tabular}

1 Licenciatura Plena em Letras Português e Respectivas Literaturas pela UnB e Especialização em Educação a Distância: Tecnologias Educacionais pelo IFPR. Assessora Especial do Gabinete da Secretaria de Estado de Educação do Distrito Federal. E-mail: valcastrog@gmail.com

2 Licenciatura Plena em Letras Português e Respectivas Literaturas pela UNESPAR. Mestre em Comunicação e Linguagens pela UTP e Doutor em Educação, Arte e História da Cultura pela Universidade Presbiteriana Mackenzie, SP. Técnico em Assuntos Educacionais na Pró-Reitoria de Extensão, Pesquisa e Inovação do IFPR e faz estágio pós-doutoral em Educação, Comunicação e Tecnologia na UDESC. E-mail: eduardo.fofonca@ifpr.edu.br

3 Licenciatura em Pedagogia pela Universidade Federal de Pelotas. É mestre e doutora em Educação pela UFPEL. Pedagoga do IFPR. E-mail: patricia.maciel@ifpr.edu.br 
Resumo: Neste artigo será discutida a dimensão educativa do uso dos dispositivos móveis, como tablets, smartphones e celulares no processo de aprendizagem ubíqua. Com base nos estudos de Pellanda (2009) e Santaella (2013) e no campo do diálogo da Educação a Distância com a Comunicação, assim como através de outras contribuições teóricas que possibilitam novas perspectivas nesta interface. Para tanto, serão analisados os processos da aprendizagem de um grupo de 61 estudantes de cursos de Educação de Jovens e Adultos (EJA) ministrado por meio da Educação a Distância (EAD). Metodologicamente, a análise deu-se a partir da aplicação de entrevistas e questionários encaminhados por e-mail, em que se objetivou analisar como os estudantes são mediados, através de dispositivos móveis, selecionando e sistematizando o conhecimento. Com esta análise concluiu-se que, praticamente, a metade dos estudantes pesquisados utiliza os dispositivos móveis como ferramenta para aprender, reconhecendo as características de dinamicidade, interatividade e autonomia propiciadas pela Internet, aproximando os indivíduos da capacidade de pesquisar e estudar no ciberespaço e, desse modo, construindo conhecimentos.

Palavras-chave: Dispositivos móveis; Comunicação ubíqua; Aprendizagem ubíqua; Educação de Jovens e Adultos; Educação a Distância.

Abstract: This article will discuss the educational dimension of the use of mobile devices such as tablets, smartphones and mobile phones ubiquitous learning process. Based on studies of Pellanda (2009) and Santaella (2013) and in the field of education dialogue Distance to the Communication, as well as through other theoretical contributions that provide new perspectives on this interface. Therefore, the processes of learning of a group of 61 students of the Youth and Adult Education courses will be analyzed (EJA) administered by Education Distance Learning $(O D L)$. Methodologically, the analysis took place from the application of interviews and questionnaires sent by email, in which it aimed to analyze how students are mediated through mobile devices, selecting and systematizing knowledge. With this analysis it was concluded that practically half of the students surveyed use mobile devices as a tool for learning, recognizing the features 
of dynamics, interactivity and autonomy afforded by the Internet, approaching individuals the ability to search and study in cyberspace and, thereby building knowledge.

Keywords: Mobile devices; Ubiquitous communication; Ubiquitous learning; Youth and Adult Education; Distance Education.

Resumen: Este artículo discutirá la dimensión educativa de la utilización de dispositivos móviles tales como tabletas, teléfonos inteligentes y los teléfonos móviles de proceso de aprendizaje ubicuos. Con base en estudios de Pellanda (2009) y Santaella (2013) y en el campo del diálogo de La educación a distancia a la comunicación, así como a través de otros aportes teóricos que proporcionan nuevas perspectivas sobre esta interfaz. Por lo tanto, se analizarán los procesos de aprendizaje de un grupo de 61 estudiantes de los cursos de jóvenes y de adultos (EJA), administrado por la Educación a Distancia (EAD). Metodológicamente, el análisis se llevó a cabo a partir de la aplicación de entrevistas y cuestionarios enviados por correo electrónico, en la que tuvo como objetivo analizar cómo los estudiantes están mediadas a través de dispositivos móviles, la selección y sistematización de conocimiento. Con este análisis se concluyó que prácticamente la mitad de los estudiantes encuestados dispositivos móviles de uso como una herramienta para el aprendizaje, el reconocimiento de las características de la dinámica, la interactividad y la autonomía que brinda Internet, acercándose a los individuos la capacidad de buscar y estudiar en el ciberespacio y, que desarrolla los conocimientos.

Palabras-clave: Dispositivos móviles; Comunicación ubicua, Aprendizaje ubicuo, Educación de Jóvenes y Adultos; Enseñanza a Distancia. 


\section{Introdução}

A realidade contemporânea vem, indubitavelmente, moldandose a recentes e rápidas transformações tecnológicas que permeiam suas relações sociais, comunicacionais e informacionais. $\mathrm{O}$ advento da Web 2.0, segunda geração de comunidades e serviços oferecidos pela internet, proporcionou condições de maior velocidade e de facilidade de uso de diversos aplicativos que alavancaram consideravelmente a quantidade de suas informações e interações; sendo, portanto, responsável pelo aumento da dinamicidade e da colaboração no ambiente on-line.

Com os dispositivos móveis interconectados vivemos, atualmente, as tecnologias sob novos formatos em relação ao tempo e ao espaço. Conforme Santaella (2013), saímos de uma interface corporal estática, com os computadores de mesa, que colocam o usuário parado diante do computador para poder entrar na internet, para situações de maior mobilidade.

Neste sentido, o presente artigo apresenta uma problematização do modo como a comunicação, realizada pelos dispositivos móveis interconectados interferem nos processos educacionais. Problematiza-se como os estudantes da Educação de Jovens e Adultos (EJA) na modalidade Educação a Distância (EAD), de uma unidade escolar que atende exclusivamente jovens e adultos na Rede Pública de Ensino do Distrito Federal, utilizam a informação disponível na "palma da mão" e como esta condição de comunicação se relaciona com a aprendizagem ubíqua. Como aprendizagem ubíqua, entende-se o processo em que os sujeitos estruturam e sistematizam o conhecimento compartilhado em redes, ou seja, quando estes podem fazer uso e estar em vários lugares e ao mesmo tempo. Segundo Neiva (2013), o ubiquitous learning ou, na tradução para o português, aprendizagem ubíqua é o aprender no ciberespaço, por meio dos dispositivos móveis, em quaisquer momentos cabendo ao usuário a escolha, a compreensão, o aprofundamento e a interconexão dessa nova virtualidade. Desse modo, apresentamos neste artigo, uma discussão na primeira parte sobre as transformações na comunicação a partir dos dispositivos móveis. Posteriormente, analisamos o impacto da comunicação na aprendizagem ubíqua desses estudantes da Educação de Jovens e Adultos na modalidade Educação a Distância. 


\section{As transformações na comunicação a partir da mobilidade}

A comunicação móvel é responsável por oportunizar uma relação entre espaços virtuais e reais de modo que as informações, os contatos, os serviços e as aplicações sejam passíveis de acesso a qualquer tempo e em todos os lugares. Tal realidade tem se tornado possível principalmente com a agregação da expansão das redes sem fio à crescente miniaturização de componentes eletrônicos. Nesse sentido, surgem os dispositivos móveis interconectados, os quais propiciam o acesso à rede mundial de computadores, internet, de qualquer espaço do globo e a qualquer tempo. Conforme Pellanda,

A comunicação móvel vem crescendo em complexidade no momento em que penetra em diferentes culturas e classes sociais. Em países como o Brasil, isso provoca um grande impacto em diferentes camadas econômicas. $\mathrm{O}$ aumento de conexões resultantes da tecnologia móvel no país tem proporcionado diferentes oportunidades e desafios aos hábitos sociais e aos limites entre espaços públicos e privados. O acesso always-on (sempre conectado) voz e dados tem aberto caminho para um novo manancial de distribuição e colaboração de informações em um contexto onde os aparelhos são 'hiper-pessoais', pois eles são realmente usados por uma só pessoa, o que não ocorre necessariamente com o computador pessoal. À medida que esses aparelhos começam a incorporar mais funcionalidades, começam a se tornar mais parecidos com computadores. Nessa perspectiva, eles têm uma grande relevância no processo de inclusão digital por serem mais baratos e estarem em condição ubíqua (2009, p. 11-12).

Essa facilidade de acesso à comunicação móvel é sentida no âmbito social, uma vez que se torna mais barato e, portanto, mais abrangente e democrático o uso da internet móvel e de todos os benefícios advindos de seu uso; e no aspecto individual, posto que esses dispositivos, apesar de sua condição "hiper pessoal", apresentam uma condição na qual se tem acesso a "tudo" independentemente do tempo e do espaço, mas se caracteriza também por tornar seu usuário "disponível" em qualquer lugar e a todo momento.

Nesse sentido, Santaella (2013) apresenta a onipresença como uma característica da ubiquidade desencadeada pelo desenvolvimento tecnológico. 
De 2006 para cá, o desenvolvimento tecnológico me levou à convicção de que a condição contemporânea de nossa existência é ubíqua. Em função da hipermobilidade, tornamo-nos seres ubíquos. Estamos, ao mesmo tempo, em algum lugar e fora dele. Tornamo-nos intermitentemente pessoas presentes-ausentes. Aparelhos móveis nos oferecem a possibilidade de presença perpétua, de perto ou de longe, sempre presença. Somos abordados por qualquer propósito a qualquer hora e podemos estar em contato com outras pessoas quaisquer que sejam suas condições de localização e afazeres no momento, o que nos transmite um sentido de onipresença. Corpo, mente e vida ubíquas (2013, p. 16).

Os avanços tecnológicos propiciaram, portanto, o acesso à comunicação permanente e, sobretudo, à informação em tempo real, independentemente da localização de seus usuários. Essa hipermobilidade proporciona a condição sedutora da possibilidade da presença perpétua, a qual gera uma falsa impressão de desenvolvimento de uma super-habilidade do homem contemporâneo em estar no controle de tudo e de todos a todo momento. Nessa esteira, caminhos favoráveis ou desfavoráveis são passíveis de ser tomados em meio à amplitude de informações, comunicações, serviços e aplicações disponíveis na Web. Dentre essas escolhas, podem ser elencadas a preservação ou a exposição de suas vidas particulares e, consequentemente, de suas intimidades; a otimização do tempo, em decorrência da redução de distâncias e das facilidades presentes no mundo on-line, ou o gasto excessivo de tempo em navegações aleatórias, dispersivas, desencontradas ou incongruentes; e, sobretudo, o ganho de aprendizagem advindo da exploração de informações e conhecimentos presentes em sites ou aplicativos, situação que se concretiza em consonância com as condições temporais, espaciais e, acima de tudo, pela curiosidade, disposição, interesse e preparo do usuário. Ainda destacando Santaella (2013) e para reforçar o sentido dado pela autora ao termo, ubiquidade é o

Atributo ou estado de algo ou alguém que se define pelo poder de estar em mais de um lugar ao mesmo tempo. A chamada computação pervasiva, computação em todos os lugares, é ubíqua. É certamente também ubíquo, onipresente, o ciberespaço informacional, uma nuvem invisível que incessantemente nos envolve e que, hoje, por meio dos dispositivos móveis, em quaisquer momentos, pode se tornar visível e pingar no dito mundo real. A disponibilidade e 
expansão do acessos à internet, potencializados pela portabilidade conectada, disseminada por toda parte, concede ao ser humano o atributo da ubiquidade, algo que, antes, lhe parecia impossível (2013, p. 127-128).

O ciberespaço informacional disponível ao mundo real via dispositivos móveis é atualmente a realidade permanente de considerável parcela da sociedade. Por meio desses recursos, é possível fazer-se "presente" em vários "espaços" em um mesmo momento. Certamente, essa condição atua como facilitadora em diversas situações; contudo, poderá também ocasionar a dispersão, se não for adequadamente empregada. Ainda quanto ao conceito de ubiquidade e aplicando-se a possibilidade de acesso às informações presentes na internet em prol da ampliação e do aprofundamento do conhecimento - as quais se encontram disponíveis desde páginas acadêmicas e respaldadas por suas instituições e seus conceituados professores e pesquisadores até blogs -, paralelamente aos conceitos acadêmicos apresentados anteriormente, será apresentada a seguir uma interessante definição de ubiquidade presente no blog "Saco de Filó e sem Fundo" (LEITE, 2008, s/d):

A palavra é difícil, mas o significado é legal. UBIQUIDADE tem origem no termo latino UBI que era utilizado como um pronome interrogativo (ONDE está você) ou mesmo como um pronome relativo (Eu vi ONDE ele estava). Mas o fato é que seja de um jeito ou de outro UBI se referia especificamente a um LUGAR. Logo, ubiquidade é a "o dom" daquele que consegue estar em vários lugares ao mesmo tempo. Dizem que Santa Clara tinha esse dom, daí ser padroeira da televisão (uma imagem que está em vários lugares ao mesmo tempo). Tem a história, inclusive de Santo Antônio de Pádua, que teria, durante um culto, saído do corpo e ido até um local distante onde seu pai estava sendo julgado para ser punido com a forca. Daí a expressão "tirar o pai da forca".

As transformações da comunicação, portanto, vem sendo consolidadas pelo advento das novas tecnologias, cuja presença é sentida também na educação. A modalidade de Educação a Distância é impulsionada pelas tecnologias comunicacionais. A flexibilidade, a rapidez e o aumento da capilaridade, ou seja, de sua abrangência são premissas presentes na realidade dessa modalidade de educação. Nesse viés, para além das formas tradicionais de se empreender a $\mathrm{EAD}$, surge um novo formato de aprendizagem que extrapola as 
estruturas de ensino-aprendizagem presentes na educação formal. Conforme pode ser observado pelo exposto por Santaella (2013),

Processos de aprendizagem abertos significam processos espontâneos, assistemáticos e mesmo caóticos, atualizados ao sabor das circunstâncias e de curiosidades contingentes. $\mathrm{O}$ advento dos dispositivos móveis intensificou esses processos, pois, graças a eles, o acesso à informação tornou-se livre e contínuo, a qualquer hora do dia e da noite. [...] Por permitir um tipo de aprendizado aberto, que pode ser obtido em quaisquer circunstâncias, a era da mobilidade inaugurou esse fenômeno inteiramente novo: a aprendizagem ubíqua. Ela não se confunde com nenhuma forma de aprendizagem existente até hoje, nem com a e-learning, que se pode traduzir por aprendizagem em ambientes virtuais. Embora tenha parentesco, também não se confunde com o que vem sendo chamado de m-learning, ou seja, aprendizagem móvel (2013, p. 23-24).

Esse novo formato de aprendizagem demanda novas práticas educativas. Essa aprendizagem aberta instiga o aprendiz a desenvolver-se como gestor de seu próprio conhecimento: elucidar suas dúvidas, buscar novos conhecimentos ou aperfeiçoar seus saberes por meio de suas próprias ações, de forma autônoma e independente. Desse modo, torna-se cada vez mais imprescindível o preparo do educador para processos educacionais compatíveis com essa nova realidade. Nessa perspectiva, Fofonca (2010) propõe que,

Portanto, educador é fazer com que crianças, jovens e adultos dialoguem com o conhecimento. Esta lógica nos faz reconhecer que, nada mais presente no cotidiano de todos, do que a própria tecnologia, o meio digital e, neste sentido, também os processos comunicacionais. Cabe, neste viés, para que se concretize a transgressão da lógica clássica de aprendizagem (o pensamento humano a partir do diálogo com o conhecimento), as formas de educação, seja formal, informal ou não-formal interajam com este meios - mídia digital, em especial os blogs. Assim, a inter-relação Comunicação/ Educação legitima-se como importante campo interdisciplinar de ação e reflexão frente ao desenvolvimento das novas tecnologias da comunicação e da informação, do deslocamento da escola como fonte privilegiada do conhecimento, enfim, da construção de uma sociedade aprendente (2010, p. 7).

Em busca de se verificar até que ponto a "construção de uma sociedade aprendente" tem se feito presente em espaço formal de edu- 
cação, serão apresentados a seguir os dados provenientes de pesquisa realizada junto a um grupo de estudantes dos segundo e terceiro segmentos da Educação de Jovens e Adultos na modalidade Educação a Distância de uma unidade escolar da Rede Pública de Ensino do Distrito Federal.

\section{Análise do acesso e uso dos dispositivos móveis na EJA}

Em busca de verificar o impacto que a ampliação do acesso aos dispositivos móveis interconectados - sobretudo os smartphones, tablets e laptops com acesso à internet - vem provocando nas comunicações e nas aprendizagens, apresentamos a pesquisa realizada com estudantes dos $2^{\circ}$ e $3^{\circ}$ Segmentos da Educação de Jovens e Adultos na modalidade Educação a Distância da única unidade escolar da Rede Pública de Ensino do Distrito Federal destinada exclusivamente à EJA, optou-se por empregar uma pesquisa qualitativa associada a fatores quantitativos, cuja finalidade é a ampliação do campo de visão, ainda que proveniente de um estreito recorte, do modo a mensurar a regularidade, a forma e as perspectivas com as quais os estudantes dessa modalidade de ensino vêm relacionando-se, apropriando-se e usufruindo desses avanços tecnológicos em sua aprendizagem. A referida unidade escolar desenvolve suas atividades, tanto na modalidade a distância como na presencial, em regime semestral. Conforme informações dos seus gestores, o índice de evasão e/ou abandono escolar nas duas modalidades de oferta de EJA é normalmente elevado. Assim, no primeiro semestre letivo de 2016, aproximadamente, 1.100 estudantes encontravam-se matriculados nos $2^{\circ}$ e $3^{\circ}$ Segmentos da Educação de Jovens e Adultos na modalidade Educação a Distância. Contudo, o período de aplicação da pesquisa coincidiu com o final do primeiro semestre letivo de 2016; desse modo, o grande número de estudantes em situação de evasão/abandono das atividades daquele semestre era uma realidade incontestável.

Nesse panorama, foi aplicado questionário contendo dez questões objetivas junto a esses jovens e adultos estudantes da EJA na modalidade EAD da mencionada escola. O questionário foi desenvolvido no Formulário Google presente no Google Drive e enviado aos estudantes por meio de e-mails. Foram disponibilizados pelos gestores escolares e coordenadores pedagógicos os e-mails de $50 \%$ do quantitativo geral dos estudantes. O prazo que a pesquisa ficou disponível para respostas 
foi de uma semana, visto que o período de aplicação do questionário coincidiu com a última semana do semestre letivo. Assim, o mencionado questionário foi encaminhado a aproximadamente 500 estudantes, dentre os quais, um pouco mais de $10 \%$ dos estudantes que tiveram seus e-mails incluídos na lista de envio respondeu às questões: um total de 61 estudantes. Contudo, apesar de aparentemente reduzido esse quantitativo de participantes, há que se considerar que, dentre outros fatores (não obrigatoriedade de retorno e, sobretudo, autor da pesquisa não pertencer ao universo desses estudantes), ao final dos semestres letivos, consoante informações da própria escola, o número de estudantes que abandona o curso é considerável.

As questões propostas abordaram alguns dados relacionados ao perfil desses estudantes (sexo, idade, segmento da EJA/EAD e atividade profissional); a tecnologia de informação e comunicação (desktop, laptops, tablets ou smartphones) mais utilizada para acesso ao seu curso EJA/EAD; a relação que esses estudantes avaliam ter entre os conhecimentos, as informações e as comunicações realizadas via internet e suas aprendizagens; a frequência com que eles utilizam a internet para aperfeiçoar seus conhecimentos e para auxiliar seus estudos, suas pesquisas e as demais demandas de seu curso EJA/EAD; a visão que eles têm com relação à abordagem dessas informações e comunicações ubíquas em suas atividades e avaliações do seu curso EJA/EAD; a forma de interação entre ele, seus professores, tutores e colegas de curso; e, por fim, a avaliação que eles fazem com relação à própria experiência na EAD.

Em busca de aplicar concretamente um instrumento que buscasse mensurar o impacto da comunicação ubíqua na aprendizagem (ubíqua) desses estudantes da Educação de Jovens e Adultos na modalidade Educação a Distância, optou-se por coletar as informações para consolidação da pesquisa, exclusivamente, via pesquisa por questionário on-line, cuja descrição dos dados e discussão dos resultados, questão por questão, serão desenvolvidas a seguir. Destaca-se que os dados apresentados e discutidos referem-se unicamente aos coletados e compilados dentre os participantes que contribuíram com a pesquisa.

Buscou-se, inicialmente, traçar um perfil desses estudantes. Para tanto, a questão um visou mensurar o quantitativo de estudantes do sexo feminino e do sexo masculino que participou da pesquisa: 
Figura 1 - Distribuição do quantitativo de estudantes da EJA/EAD por sexo.

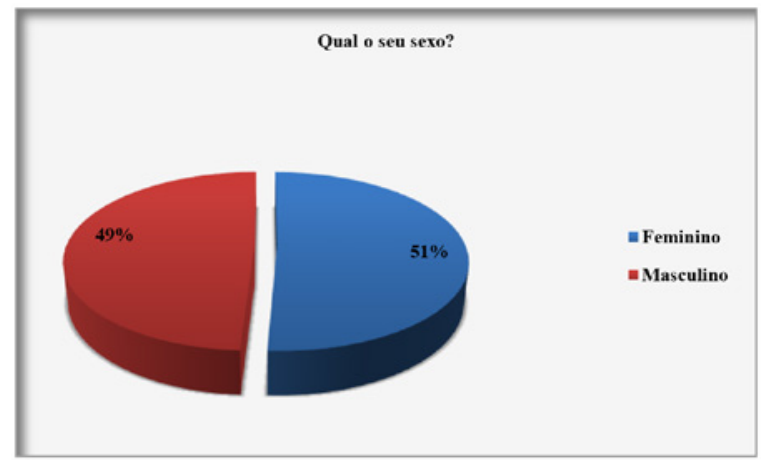

Fonte: Extraído de dados de pesquisa própria aplicada em jun./jul. 2016.

Os resultados mostram que, dentre os participantes da pesquisa, há uma relativa paridade entre os sexos feminino e masculino, uma vez que há uma ínfima diferença de $2 \%$ a mais para o sexo feminino. Não obstante, reitera-se que os dados aqui apresentados restringem-se apenas aos participantes da pesquisa e, não, à totalidade dos matriculados, haja vista não ser prudente mesclar dados gerais dos matriculados com os dos participantes da pesquisa, uma vez que poderíamos incorrer em comparações inconsistentes.

A questão dois aborda a faixa etária do estudante da Educação de Jovens e Adultos na modalidade Educação a Distância que participou da pesquisa:

Figura 2 - Distribuição dos estudantes da EJA/EAD por faixa etária.

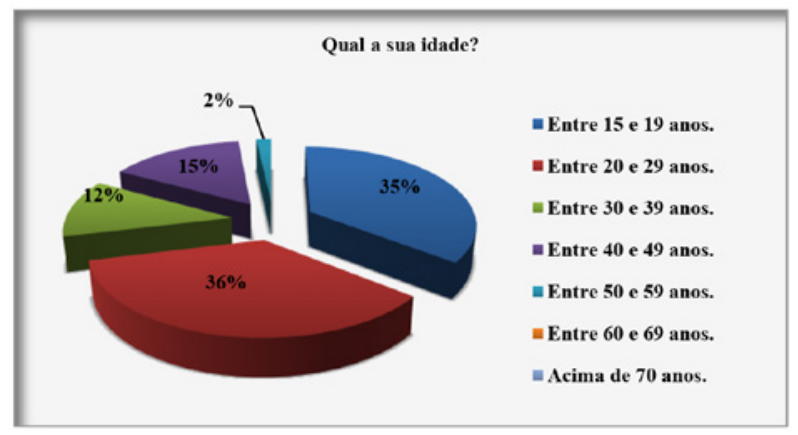

Fonte: Extraído de dados de pesquisa própria aplicada em jun./jul. 2016. 
Os resultados mostram que, dentre os participantes da pesquisa, o maior grupo (36\%) corresponde à faixa etária "entre 20 e 29 anos", seguida de perto (35\%) pela faixa etária "entre 15 e 19 anos", o que simboliza a representativa maioria (71\%) dos estudantes participantes da pesquisa com idade entre 15 e 29 anos de idade. Em seguida, em quantidade também bastante aproximada entre si, encontram-se as faixas etárias "entre 30 e 39 anos" (12\%) e "entre 40 e 49 anos" (15\%). Por fim, dentre os participantes da pesquisa, um pequeno grupo (2\%) da faixa etária "entre 50 e 59 anos". Registra-se não ter havido nenhum representante das faixas etárias "entre 60 e 69 anos" e "acima de 70 anos" participado da pesquisa.

A questão três buscou verificar o segmento da EJA/EAD que está cursando o jovem ou adulto que participou da pesquisa:

Figura 3 - Distribuição dos estudantes da EJA/EAD por Segmento da EJA.

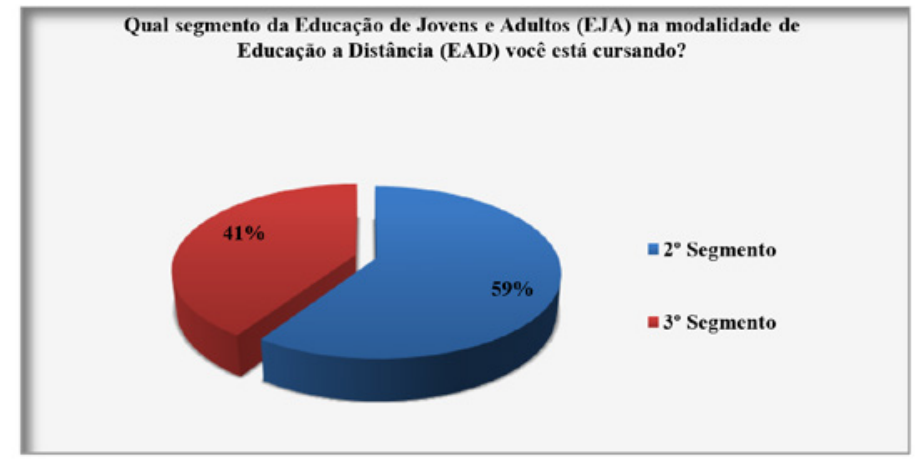

Fonte: Extraído de dados de pesquisa própria aplicada em jun./jul. 2016.

Os resultados mostram que, dentre os participantes da pesquisa, o maior grupo (59\%) estava cursando o $2^{\circ}$ Segmento da EJA/EAD, enquanto o menor grupo (41\%) pertencia ao $3^{\circ}$ Segmento da EJA/ EAD. Há que se ponderar inclusive que esse registro é compatível com o quantitativo de 35\% (Questão 2) que está na faixa etária entre 15 e 19 anos, visto que, para ingressar no $3^{\circ}$ Segmento, o jovem deve ter, no mínimo, 18 anos de idade.

A questão quatro buscou verificar a condição atual de inserção no mundo do trabalho do jovem ou adulto que participou da pesquisa: 
Figura 4 - Distribuição dos estudantes da EJA/EAD por exercício de atividade

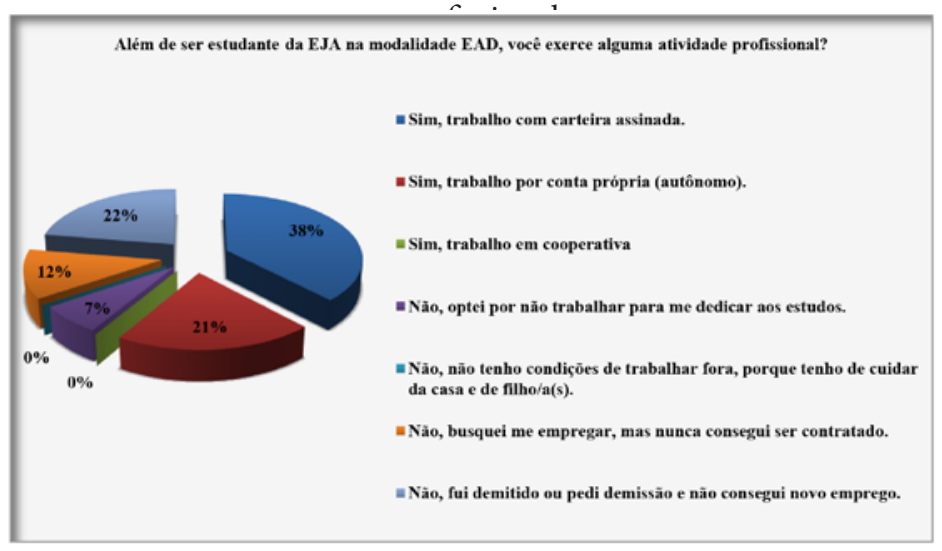

Fonte: Extraído de dados de pesquisa própria aplicada em jun./jul. 2016.

Os resultados mostram que, dentre os jovens e adultos participantes da pesquisa que atualmente se encontram inseridos no mundo trabalho, o maior grupo (38\%) está formalmente empregado com carteira assinada; enquanto um grupo também expressivo (21\%) dispõe de emprego informal como autônomo; e nenhum registro foi feito como membro de cooperativa. Dentre os pesquisados que não se encontram atualmente inseridos no mundo trabalho, está o percentual considerável de $22 \%$ que se identificou na situação de demitido/pediu demissão e não conseguiu novo emprego; seguido do percentual de $12 \%$ que buscou se empregar, mas não conseguiu ser contratado; enquanto $7 \%$ declarou não trabalhar por escolha própria e com a finalidade de se dedicar aos estudos; e, por fim, não houve qualquer registro de estudante que afirmou não poder trabalhar para cuidar da casa e de filho/a(s).

Portanto, dos 61 jovens e adultos que participaram da pesquisa, $59 \%$ deles encontra-se inserido no mundo do trabalho; enquanto $41 \%$ declarou-se fora do mercado formal ou informal de trabalho no momento em que responderam à pesquisa. Destes $41 \%$, apenas $7 \%$ está fora do mundo do trabalho por opção; enquanto 34\% dos respondentes gostaria de estar trabalhando, mas declararam não conseguir inserção ou reinserção no mercado formal ou informal de trabalho.

Após a aplicação de algumas questões voltadas a delinear o perfil 
médio desses estudantes, as questões a seguir visam traçar o perfil desses estudantes com relação às tecnologias de comunicação e informação (TDIC), a comunicação ubíqua e, sobretudo, a aprendizagem ubíqua. Para tanto, a questão cinco buscou averiguar a tecnologia de comunicação e de informação mais utilizada pelo jovem ou adulto que participou da pesquisa para acessar seu curso EJA na modalidade EAD.

Figura 5 - Distribuição dos estudantes da EJA/EAD por tecnologia de informação e comunicação mais utilizada para acessar o curso EJA/EAD.

Qual das tecnologias de comunicação e de informação você mais utiliza para acessar o seu curso EJA na modalidade EAD?
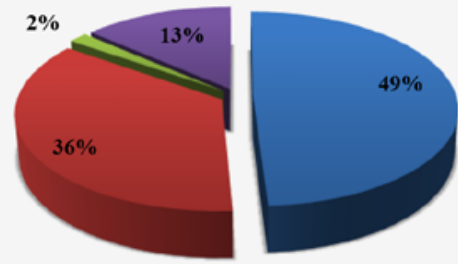

E Desktop (computador de mesa) com acesso à internet.

- Laptop (computador portátil) com acesso à internet.

= Tablet (computador portátil, pequeno e com tela sensivel ao toque) com acesso à internet.

- Smartphone (celular com tecnologias avançadas) com acesso à internet.

Fonte: Extraído de dados de pesquisa própria aplicada em jun./jul. 2016.

Quanto à tecnologia de informação e de comunicação mais utilizada pelos jovens e adultos para desenvolver suas leituras, assistir às videoaulas, realizar as atividades pedagógicas propostas e, especialmente, relacionar-se com seus professores, tutores e colegas, a mais declaradamente utilizada pelos estudantes foi o desktop (49\%), seguida do laptop (36\%) e do smartphone (13\%); e, por fim, apenas um quantitativo mínimo (2\%) disse utilizar tablet.

Contudo, cumpre destacar que apenas recentemente a plataforma desse curso Educação de Jovens e Adultos na modalidade Educação a Distância foi compatibilizada para acesso por meio de 
smartphone. Desse modo, em decorrência de condições estruturais, observac-se que a cultura imperante até então nessa unidade escolar foi a de utilização de desktops ou laptops para acesso à plataforma da modalidade EAD.

A questão seis busca verificar se o jovem ou adulto que participou da pesquisa considera que conhecimentos, informações, conversas e outras experiências estabelecidas via internet (comunicação ubíqua) são importantes para sua aprendizagem:

Figura 6 - Distribuição dos estudantes da EJA/EAD por avaliação quanto à importância da comunicação ubíqua para sua aprendizagem.

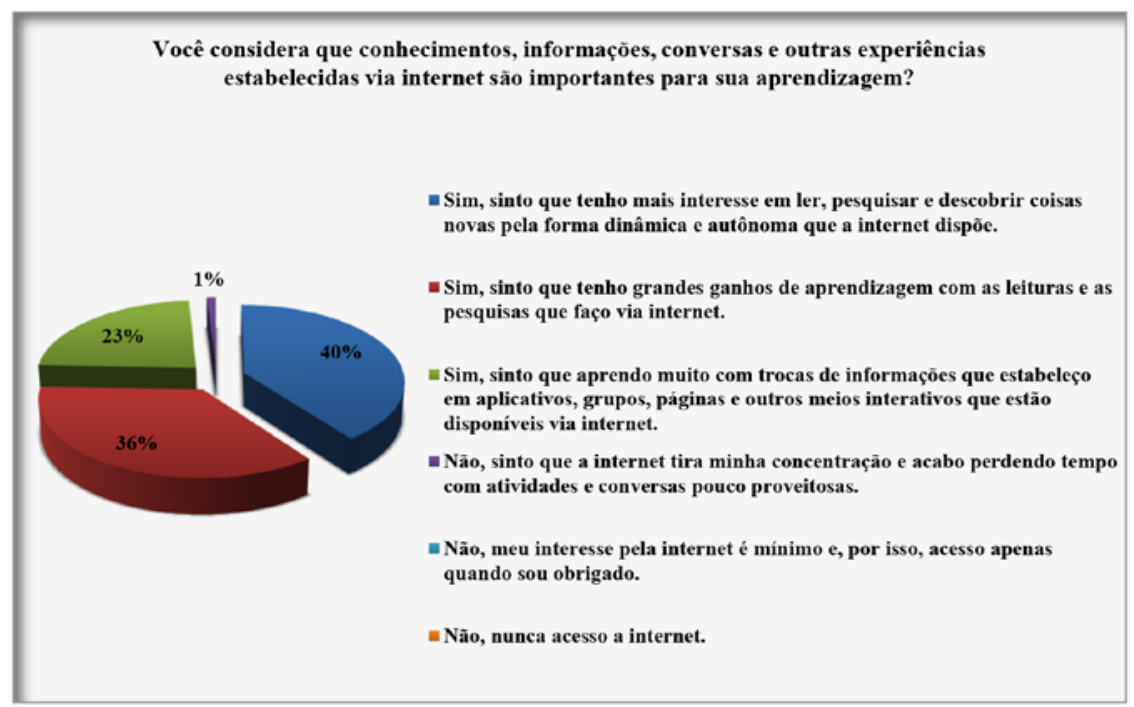

Fonte: Extraído de dados de pesquisa própria aplicada em jun./jul. 2016.

Quanto à questão referente à utilização da comunicação ubíqua para ganho de conhecimento/aprendizagem, tendo em vista que os pesquisados puderam optar por mais de um item como resposta, na análise das considerações apresentadas, foram agrupadas as respostas favoráveis e as desfavoráveis ao questionamento apresentado, de modo que, como resultado, registra-se que quase totalidade dos estudantes da EJA/EAD pesquisados (99\%) considera demonstrar mais interesse em ler, pesquisar, ter acesso a novos conhecimentos 
e trocar experiências e informações em decorrência das características dinamicidade, interatividade e autonomia propiciadas pela internet; enquanto que apenas $1 \%$ declarou que a internet tira-lhe a concentração e, portanto, acaba provocando perda de tempo com atividades pouco proveitosas.

A questão sete aborda a frequência com a qual o jovem ou adulto que participou da pesquisa utiliza recursos, informações e comunicações via internet para aperfeiçoar seus conhecimentos e para apoiar o desenvolvimento das atividades do curso EJA na modalidade EAD.

Figura 7 - Distribuição dos estudantes da EJA/EAD por frequência de acesso à comunicação ubíqua para a aprendizagem e o desenvolvimento de seu curso.

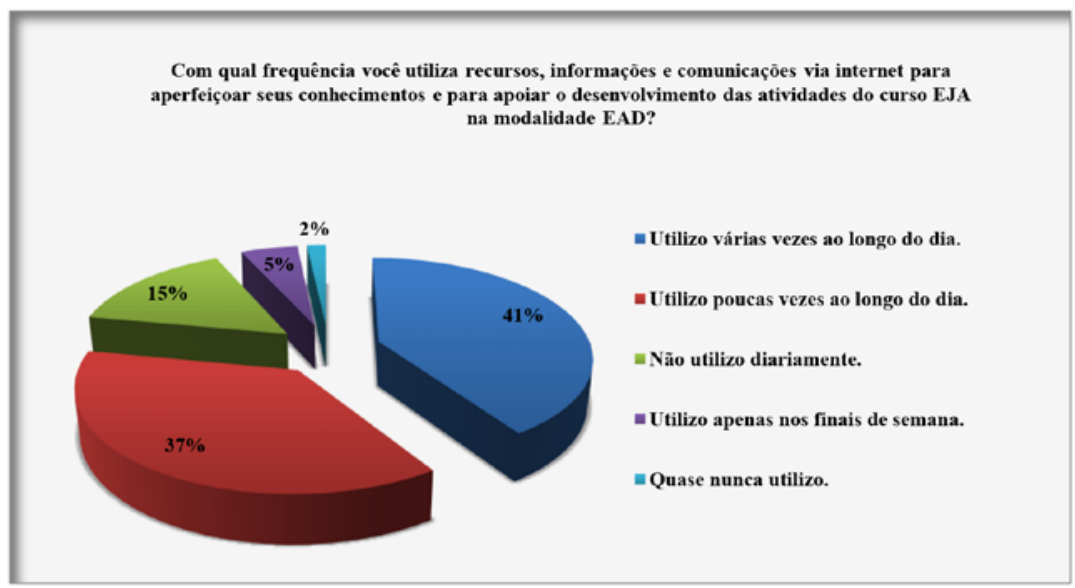

Fonte: Extraído de dados de pesquisa própria aplicada em jun./jul. 2016.

Os resultados mostram que, dentre os jovens ou adultos participantes da pesquisa, $41 \%$ acessa recursos, informações e comunicações via internet várias vezes ao longo do dia; $37 \%$ acessa poucas vezes ao longo do dia; $15 \%$ não utiliza diariamente; $5 \%$ utiliza apenas nos finais de semana; e, por fim, um pequeno grupo (2\%) quase nunca acessa à internet. Desse modo, os dados apresentados demonstram que $78 \%$ dos estudantes pesquisados utilizam diariamente a internet. Portanto, há que se registrar a presença diária da comunicação e aprendizagem ubíquas nas vidas da expressiva maioria dos jovens e adultos pesquisados. 
A questão oito busca verificar a forma pela qual o jovem ou o adulto que participou da pesquisa considera que suas buscas por conhecimentos, informações, conversas e outras experiências estabelecidas via internet estão sendo abordadas em seu curso EJA na modalidade EAD.

Figura 8 - Distribuição dos estudantes da EJA/EAD por avaliação quanto à forma de utilização e aplicação da comunicação ubíqua no desenvolvimento de seu curso EJA/EAD.

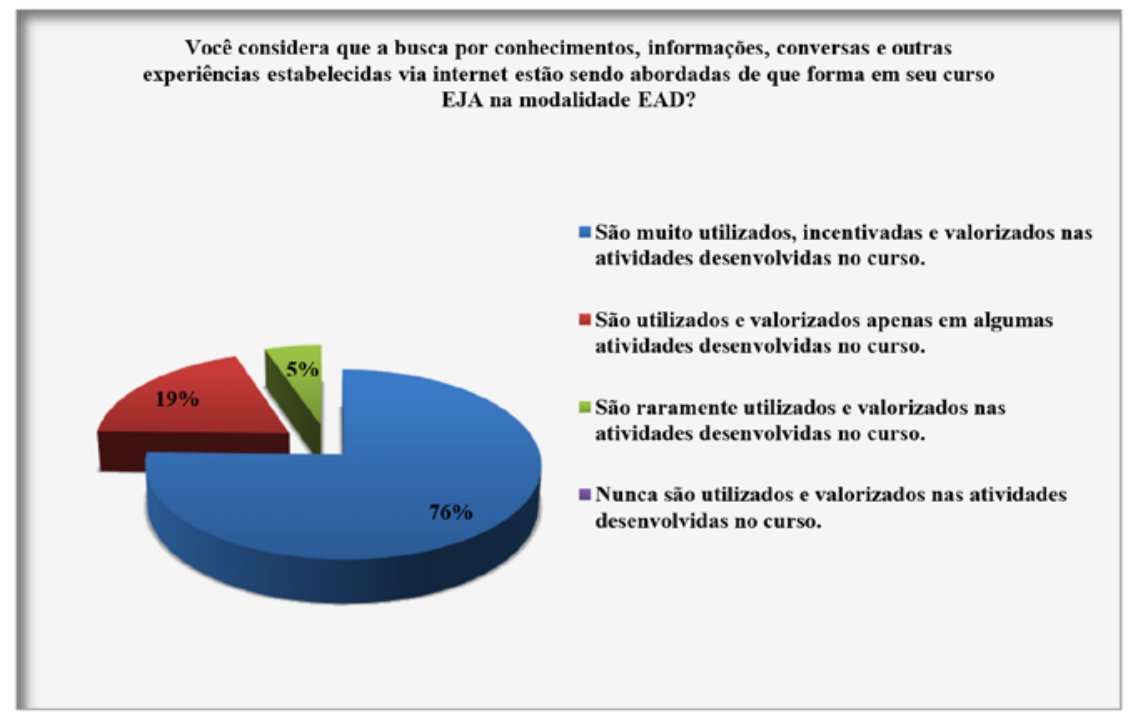

Fonte: Extraído de dados de pesquisa própria aplicada em jun./jul. 2016.

Os resultados apresentados demonstram que, dentre os jovens e adultos participantes da pesquisa, a grande maioria (76\%) avalia que as buscas por conhecimentos, informações, conversas e outras experiências estabelecidas via internet (comunicação ubíqua) são muito utilizadas, incentivadas e valorizadas nas atividades desenvolvidas no seu curso EJA/EAD; e 19\% avalia que são valorizadas apenas em algumas atividades; enquanto, um pequeno número (5\%) considera que raramente são utilizadas; e, por fim, nenhum estudante declarou considerar que essas buscas não são utilizadas nas atividades desenvolvidas em seu curso.

Os dados demonstram, portanto, que quase a totalidade (95\%) dos estudantes pesquisados considera que as atividades pedagógicas 
desenvolvidas ao longo de seu curso EJA/EAD utilizam da comunicação ubíqua como instrumento pedagógico. Com isso, constatase também que, não apenas os estudantes estão utilizando das comunicações e aprendizagens ubíquas, mas o sistema de ensino na modalidade a distância tem se apropriado desses mecanismos como ferramentas pedagógicas.

A questão nove busca verificar como o jovem ou o adulto que participou da pesquisa avalia sua sua interação com seus professor/ es, tutor/es, e colegas em seu curso EJA na modalidade EAD.

Figura 9 - Distribuição dos estudantes da EJA/EAD pela avaliação quanto à utilização da comunicação ubíqua entre os participantes do curso EJA/EAD.

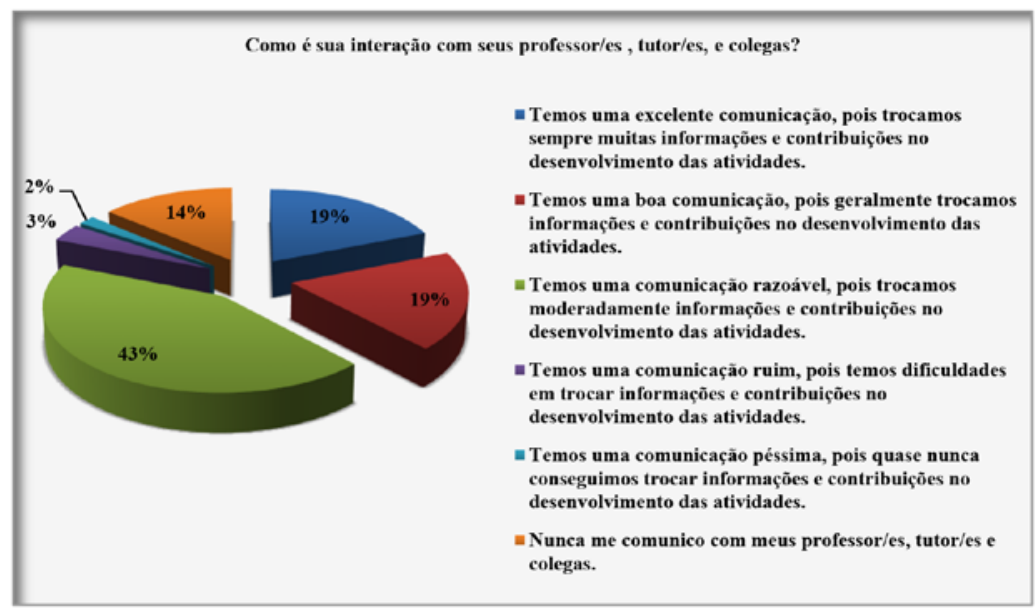

Fonte: Extraído de dados de pesquisa própria aplicada em jun./jul. 2016.

Os resultados demostram que, dentre os jovens e os adultos participantes da pesquisa, a grande maioria (43\%) avalia ter uma comunicação (ubíqua) razoável entre ela/e, seus professores, seus tutores e seus colegas; 19\% avalia ter uma excelente comunicação; outros 19\% avalia ter uma boa comunicação; enquanto, 14\% diz nunca se comunicar; 3\% afirma ter um comunicação ruim; e, por fim, 2\% considera ter uma comunicação péssima entre ela/e e os demais sujeitos participantes de seu curso EJA/EAD. Assim, 81\% dos estudantes avalia que a comunicação em seu curso EJA/EAD varia entre excelente e razoável. Desse modo, observa-se que a distância espaço temporal não é sentida pela grande maioria como barreira comunicacional entre os 
partícipes dessa tríade relação pedagógica: professor/tutor-estudante; estudante-estudante; e estudante-atividade pedagógica.

Por fim, a questão dez aborda a forma como o jovem ou o adulto que participou da pesquisa avalia sua experiência como estudante do curso de Educação de Jovens e Adultos na modalidade Educação a Distância.

Figura 10 - Distribuição dos estudantes da EJA/EAD pela avaliação de sua experiência como estudante na modalidade EAD.

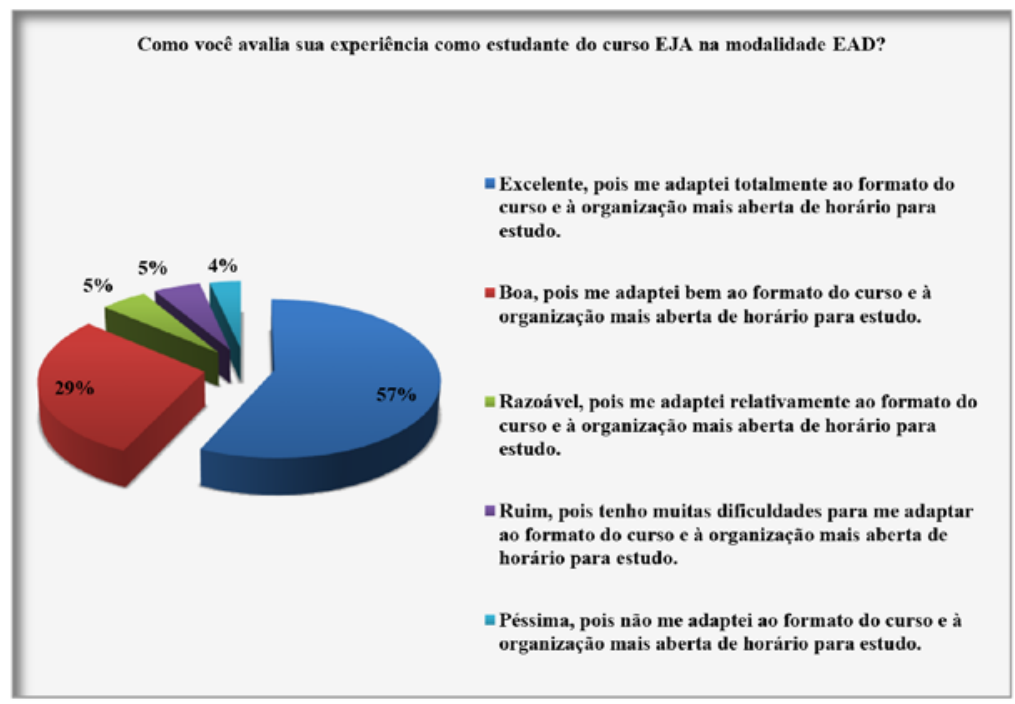

Fonte: Extraído de dados de pesquisa própria aplicada em jun./jul. 2016.

Quanto à avaliação que o jovem ou o adulto participante da pesquisa fez relativamente à sua experiência como estudante da EJA na modalidade EAD, $57 \%$ considerou excelente; $29 \%$ avaliou como boa; $5 \%$ considerou razoável; enquanto, outros 5\% diz ter sido ruim; e $4 \%$ avaliou como péssima. Nesse sentido, pelos dados apresentados, pode-se constatar que a grande maioria (86\%) avaliou ter tido uma excelente/boa experiência no seu curso na modalidade EAD. Constatação bastante favorável à modalidade de educação a distância, cuja implantação é relativamente nova no Brasil e, sobretudo, ao se considerar as inúmeras dificuldades de acesso às TDIC e à própria educação regular, características marcantes do perfil do estudante aqui 
pesquisado, os quais são jovens e adultos da rede pública de ensino que, em sua maioria, dispõem de baixa renda e, devido a fatores econômicos, sociais e até culturais, tiveram pouca ou nenhuma possibilidade de acesso e/ou continuidade dos estudos na "idade certa".

\section{Considerações finais}

A comunicação ubíqua surge como responsável pela quebra de barreiras comunicacionais, informacionais e, sobretudo, tempo-espacial. Esse novo paradigma comunicacional interfere diretamente no acesso ao conhecimento. Contudo, quais os impactos concretos do acesso à comunicação ubíqua podem ser observados na aprendizagem (ubíqua) dos estudantes? Essas foram as indagações que alicerçaram a pesquisa aqui empreendida. E, a partir dessa inquietação, o corte delimitado para aplicação das ferramentas de avaliação (aplicação de questionário on-line para os estudantes e conversas com os gestores escolares e coordenadores pedagógicos) foi o de estudantes da Educação de Jovens e Adultos, na modalidade Educação a Distancia, da Rede Pública de Ensino do Distrito Federal.

A partir dos dados apresentados na pesquisa realizada junto a esses estudantes observou-se que, apesar de ainda ser expressivo o acesso à plataforma do referido curso por meio de desktop (49\%), a utilização dos dispositivos móveis (laptop, tablet e smartphone) aparece com um total de $51 \%$ de acesso. Importante reiterar que apenas recentemente foi disponibilizado a esses estudantes a possibilidade de acesso à plataforma do curso EJA/EAD via smartphones e tablets. Desse modo, percebe-se que tanto a unidade escolar e seu corpo docente quanto os estudantes estão em fase de adaptação à ampliação do acesso à plataforma do curso por meio desses dispositivos móveis interconectados.

Contudo, apesar da condição estrutural incipiente apresentada, observou-se que, para os estudantes pesquisados, as buscas por conhecimentos, informações, comunicações e outras experiências estabelecidas por eles via internet (comunicação ubíqua) estão sendo muito utilizadas $(76 \%)$ ou utilizadas em algumas atividades desenvolvidas no curso (19\%); enquanto que apenas 5\% diz que raramente há utilização da comunicação ubíqua em suas atividades pedagógicas desenvolvidas. Indubitavelmente é bastante aprazível constatar que 
nenhum dos estudantes pesquisados considera que seus conhecimentos, informações e comunicações frutos da comunicação ubíqua são desconsiderados em seu curso. Os dados demonstram, portanto, haver apropriação de aprendizagem por parte da maioria considerável desses estudantes via dispositivos móveis interconectados, o que consubstancia a efetivação de aprendizagem ubíqua de modo extremamente relevante em suas vidas diárias.

Dentre os dados analisados na pesquisa, outra constatação prazenteira de se reiterar é o fato de que quase totalidade dos estudantes da EJA/EAD pesquisados (99\%) considera demonstrar mais interesse em ler, pesquisar, ter acesso a novos conhecimentos e trocar experiências e informações em decorrência das características dinamicidade, interatividade e autonomia propiciadas pela internet, o que sugere que a comunicação ubíqua para esse grupo de estudantes está bastante aproximada da aprendizagem ubíqua. Nesse contexto, observa-se que a facilidade de acesso às informações provenientes do uso dos dispositivos móveis interconectados vem aproximando os indivíduos da capacidade de pesquisar e suprir suas necessidades e curiosidades por novas informações, conhecimentos e comunicações quase instantaneamente.

Na relação ensino-aprendizagem, observa-se que a comunicação ubíqua vem propiciando o desenvolvimento, por parte dos professores/ tutores e dos estudantes, a ampliação do conhecimento para além do anteriormente previsto apenas nas grades curriculares. Desse modo, essa nova realidade demanda do ambiente escolar, seja presencial ou a distância, a apropriação dessas novas ferramentas tecnológicas como aliadas ao trabalho pedagógico e, mais ainda, como suporte ao desenvolvimento de estudantes autônomos, críticos, criteriosos, curiosos e criativos em sua construção, seleção e consolidação de saberes.

Por todo o exposto, pode-se reconhecer que o novo contexto hipermidiático demonstra ser imprescindível que a escola busque assumir a função de complementar suas potencialidades de ensino para as aprendizagens por meio das novas tecnologias. Hoje não há como omitir a forte influência dos dispositivos móveis interconectados na realidade dos estudantes. No entanto, a fim de que seja ampliada e consolidada ainda mais a aproximação entre comunicação e aprendizagem ubíquas, há de se buscar um maior investimento na conjugação das novas tecnologias com os projetos educacionais e as 
propostas pedagógicas. Afinal, a aprendizagem (ubíqua) ocorre, tão somente, quando a informação é efetivamente interiorizada de modo a propiciar o seu uso em tempo futuro.

A fronteira entre comunicação (ubíqua) e aprendizagem (ubíqua) promove condições diversificadas de acesso ao conhecimento disponibilizados, até então, somente pela educação formal. Consequentemente o desenvolvimento da prática pedagógica com a integração dos dispositivos móveis nas unidades escolares asseguram a consonância entre novos estilos de aprendizagem, cada vez mais comunicacionais, e sua relação intrínseca com os progressivos avanços tecnológicos que permeiam a sociedade contemporânea.

\section{REFERÊNCIAS}

ANDRÉ, M. Questões sobre os fins e sobre os métodos de pesquisa em educação. Revista Eletrônica de Educação, v. 1, n. 1, set. 2007. Disponível em: $<$ http://www.reveduc.ufscar.br/index.php/reveduc/article/view/6>. Acesso em: 5 jun. 2016.

FOFONCA. E. Conexões entre Comunicação e Educação: Novas Sensibilidades e Novos Saberes. Primeira Revista Eletrônica em América Latina Especializada en Comunicación, n. 76, Mai. 2011. Disponível em: <http://www.razonypalabra.org. mx/N/N76/varia/2a\%20entrega/18_Fofonca_V76.pdf>. Acesso em: 5 jun. 2016.

Os Blogs como Mídia Digital na Educação: Diálogos Possíveis.

Primeira Revista Eletrônica em América Latina Especializada en Comunicación, n. 74, Nov. 2010. Disponível em: <http://www.razonypalabra.org.mx/N/N74/ VARIA74/06FofoncaV74.pdf>. Acesso em: 5 jun. 2016.

\section{. Entre as Práticas de (Multi)letramentos e os Processos}

de Aprendizagem Ubíqua da Cultura Digital: as percepções estéticas dos educadores das linguagens. Tese de Doutorado em Educação, Arte e História da Cultura da Universidade Presbiteriana Mackenzie, São Paulo, 2015.

FRANCELIN, M. M. A epistemologia da complexidade e a ciência da informação. Disponível em: <http://www.scielo.br/pdf/ci/v32n2/17034.pdf. Acesso em: 5 jun. 2016.

LEITE, M. O dom da ubiquidade - o que é isso? Disponível em: $<$ http://www. sacodefilo.com/2008/06/o-dom-da-ubiqidade-o-que-isso.html>, jun. 2008. Acesso em: 15 jul. 2016. 
NEIVA, U. u-Learning: Você conhece a aprendizagem ubíqua? Disponível em: $<$ http://www.e-lead.com.br/site/u-learning-voce-conhece-a-aprendizagemubiqua/>, nov. 2013. Acesso em: 2 jul. 2016.

NOGUEIRA, E. J.; SOARES, M. L. A. Desafios educacionais na modernidade líquida: cotidiano, medo e indiscipline. Revista Educação e Cultura Contemporânea, Sorocaba, v. 12, n. 27. Disponível em: <http://periodicos. estacio.br/index.php/reeduc/article/viewFile/354/631>. Acesso em: 5 jun. 2016.

OLIVEIRA, M. K. de. Jovens e adultos como sujeitos de conhecimento e aprendizagem. Revista Brasileira de Educação. Associação Nacional de PósGraduação - ANPED. Set/Out/Nov/Dez 1999, p. 59-73, nº 12. São Paulo.

PELLANDA, E. C.. Comunicação móvel no contexto brasileiro. In. LEMOS, A.; JOSGRILBERG, F. Comunicação e mobilidade: aspectos socioculturais das tecnologias móveis de comunicação no Brasil Salvador : EDUFBA, 2009. pp. 11-18.

RODRIGUEZ, M. I. F.; SALGADO, R. F. M. EAD e educação de adultos: teorias adequadas fazem toda a diferença quando a questão é qualidade. 14. CIAED, 2008. Disponível em: <http://www.abed.org.br/congresso2008/ tc/55200845628PM.pdf>. Acesso em: 5 jun. 2016.

SANTAELLA, L. Comunicação ubíqua: repercussões na cultura e na educação. São Paulo: Paulus, 2013. 